\title{
Necessary and sufficient conditions for communication of diet preferences by Norway rats
}

\author{
BENNETT G. GALEF, JR. \\ McMaster University, Hamilton, Ontario, Canada
}

\begin{abstract}
Rats that (1) either ate a small sample of one or two foods (Diet A or Diet B) or interacted with a demonstrator that had eaten either Diet A or Diet B, (2) ate both Diets A and B in succession, and (3) were made ill preferred whichever of the two foods they or their respective demonstrators had eaten. Although eating a food and interacting with a demonstrator that had eaten that food were each sufficient to enhance preference for the food, eating particles of food clinging to the fur of a demonstrator was not necessary for enhancement of preference for the food that a demonstrator ate. Subjects exposed to demonstrators they could not physically contact still exhibited enhanced preference for the food that their demonstrator had eaten. The data were discussed as indicating that although smelling a diet, eating a diet, and interacting with a demonstrator that had eaten a diet can each enhance preference for that diet, it cannot be inferred that eating a food, smelling a food, and interacting with a demonstrator that has eaten a food each affect diet preference via the same process.
\end{abstract}

The results of a number of studies have shown that after a naive observer rat interacts with a demonstrator rat that previously ate a food, the observer exhibits an enhanced preference for the food that its demonstrator ate (Galef, 1986b, 1987; Galef, Kennett, \& Stein, 1985; Galef, Kennett, \& Wigmore, 1984; Galef \& Stein, 1985; Galef \& Wigmore, 1983; Posadas-Andrews \& Roper, 1983). Analyses of the conditions that result in such social enhancement of observers' food preferences have repeatedly indicated that exposure of a subject to a demonstrator that has either eaten a food or been dusted with a food is sufficient to enhance an observer's preference for that food. On the other hand, in situations similar to those resulting in social enhancement of diet preference, neither simply smelling a food nor eating samples of a food has been found to increase a subject's subsequent preference for the food to which the subject was exposed (Galef, 1989; Galef \& Kennett, 1987; Galef et al., 1985; Galef \& Stein, 1985).

There are two reasons why my co-workers and I have persevered in looking for simple-exposure-induced enhancement of food preference in rats of comparable magnitude to that induced by exposure to demonstrators that have eaten a food. First, it has always seemed intuitively likely to us that eating or smelling a food might have ef-

The research presented here was supported by grants from the Natural Sciences and Engineering Research Council of Canada and the McMaster University Research Board. I thank Elaine Whiskin and Ted Newbigging for their technical assistance, and Mertice Clark and Laurel McQuoid for comments on earlier drafts of the manuscript. Correspondence should be addressed to Bennett G. Galef, Jr., Department of Psychology, McMaster University, Hamilton, Ontario, L8S 4K1, Canada. fects on later food preference similar to the effects of interacting with a conspecific that had eaten a food (for reviews, see Hall, 1980; Hill, 1978). Second, two pioneering studies of social influence on diet preference, done by Posadas-Andrews and Roper (1983), provided data consistent with the hypothesis that socially induced changes in diet preference were a result of observers' simply smelling or eating particles of food clinging to their respective demonstrators.

Following many failures in my laboratory to find reliable effects on preference for a diet of either simple exposure to that diet or eating samples of that diet, it was rewarding finally to discover a situation in which feeding a sample of food to a rat affected its later diet choice to almost exactly the same extent as did exposure of a subject to a demonstrator that had eaten the food. Below, I first describe the procedure that produced what was, at least in my laboratory, an anomalous result-a substantial effect of eating a food on later preference for that food.

Of course, to understand social influences on diet choice, the important issue is not whether both eating a food and interacting with a demonstrator that has eaten a food increase preference for that food. Rather, one wants to know whether the effects of demonstrators on the food preferences of their observers can be understood in terms of effects on observer rats' preferences of eating particles of food that may cling to the fur or vibrissae of their respective demonstrators. Therefore, in a second experiment, I determined whether or not eating a sample of diet, an action shown in the first experiment to be sufficient to alter an observer's later diet preference, was also necessary to produce demonstrator-induced changes in observers' diet preferences. 


\section{EXPERIMENT 1}

Results of previous studies of the effects of socially transmitted information on taste-aversion learning (Galef, $1986 \mathrm{a}, 1986 \mathrm{~b}, 1987)$ have shown that a naive rat that (1) interacted for 30 min with a demonstrator rat fed one of two diets (either Diet A or Diet B); (2) ate Diets A and $B$ in succession; and (3) was made ill, subsequently preferred whichever of the two diets its demonstrator had eaten. That is, those observers whose demonstrators had eaten Diet A preferred Diet A, whereas those observers whose demonstrators had eaten Diet B preferred that diet. In the present experiment, in addition to allowing some subjects to interact with demonstrators that had been fed either Diet A or Diet B during (1) above, I allowed other subjects either to eat small samples of Diet A or Diet B or to smell samples of Diet A or Diet B. Each subject then proceeded through the experimental procedure and was later tested for its preference between Diets A and B.

\section{Method}

\section{Subjects}

Forty-six female 42-day-old Long-Evans rats born in the McMaster vivarium to breeding stock acquired from Charles River Canada (St. Constant, Quebec) served as subjects. Twelve additional 56-day-old female rats that had served as observers in previous experiments served as demonstrators in the present experiment. The subjects were randomly assigned to one of the three conditions described in Step 3 below.

\section{Apparatus}

The subjects and demonstrators were housed individually throughout the experiment, the subjects in one compartment of $22 \times 48$ $\times 27.5 \mathrm{~cm}$ wire-mesh hanging cages divided in half by .5 -in. screen partitions, the demonstrators in $22 \times 24 \times 27.5 \mathrm{~cm}$ hanging cages.

\section{Procedure}

The treatment of the subjects and demonstrators during the experiment took place as follows:

Step 1. The subjects and demonstrators were introduced into their respective cages and placed on a 23-h, food-deprivation schedule, receiving powdered Purina Rodent Laboratory Chow No. 5001 for $1 \mathrm{~h} /$ day for 2 consecutive days.

Step 2. Following a third 23-h period of food deprivation, each demonstrator was offered, for $1 \mathrm{~h}$, a food cup containing either cocoa-flavored diet (Diet COC; 6 demonstrators) or cinnamonflavored diet (Diet CIN; 6 demonstrators). (Diet COC = powdered Purina Laboratory Rodent Chow adulterated $2 \%$ by weight with Hershey's cocoa; Diet CIN = powdered Purina Laboratory Rodent Chow adulterated $1 \%$ by weight with McCormick's Pure Ground Cinnamon.)

Step 3. Immediately following the feeding of each demonstrator, each was introduced individually into the cage of a subject and each demonstrator-subject pair was left undisturbed for $.5 \mathrm{~h}$ to interact freely. Six subjects interacted for $.5 \mathrm{~h}$ with a demonstrator previously fed Diet CIN, and 6 subjects with a demonstrator previously fed Diet COC.

While each of these 12 subjects was interacting with its respective demonstrator, an additional 12 subjects were each given $.5 \mathrm{~h}$ access to a food cup containing $.3 \mathrm{~g}$ of either Diet CIN (6 subjects) or Diet COC (6 subjects).

At the same time, 22 more subjects were each given .5-h access to a food cup half filled with either Diet CIN (11 subjects) or Diet $\mathrm{COC}$ (11 subjects) and covered with a piece of screen (.5-in. mesh) that allowed the subjects to smell the food placed in their respective cages, but prevented them from eating that food. Data from 1 of the subjects assigned to this condition had to be discarded when the subject upset its food cup and ate some of the food that it spilled.

Step 4. At the end of Step 3, the demonstrator or food cup was removed from each subject's cage and replaced with a weighted food cup containing Diet COC. This food cup was left in the subject's cage for $15 \mathrm{~min}$. At the end of this first 15-min feeding period, the food cup containing Diet COC was removed and replaced, for 15 min, with a food cup containing Diet CIN.

Step 5. Immediately following termination of the second 15-min feeding period, each subject received an intraperitoneal (i.p.) injection of $1 \%$ of body weight $(1 \% \mathrm{w} / \mathrm{v}) \mathrm{LiCl}$ solution.

Step 6. One hour following injection, pellets of Purina Rodent Laboratory Chow No. 5001 were placed in each subject's cage, and each was given $24 \mathrm{~h}$ to recover from toxicosis.

Step 7. Following the $24-\mathrm{h}$ recovery period, each subject was offered, for $22 \mathrm{~h}$, a simultaneous choice of weighed samples of Diets $\mathrm{CIN}$ and $\mathrm{COC}$. At the end of the 22-h test period, the experimenter determined each observer's intake of Diet CIN and Diet COC and calculated the percentage of Diet COC eaten by each subject during the 22-h test.

\section{Results and Discussion}

The main results of Experiment 1 are presented in Figure 1, which shows the mean amount of Diet CIN ingested by subjects in each of the three experimental conditions, as a percentage of the total amount of CIN plus $\mathrm{COC}$ ingested. As is evident from inspection of the figure, and as statistical tests confirmed (Mann-Whitney $U$ tests; see Figure 1 for $U$ and $p$ values), both the subjects that interacted with a demonstrator during Step 3 of the procedure and the subjects that ate .3-g samples of either Diet CIN or Diet COC during Step 3 of the procedure exhibited substantial effects of the diet they experienced

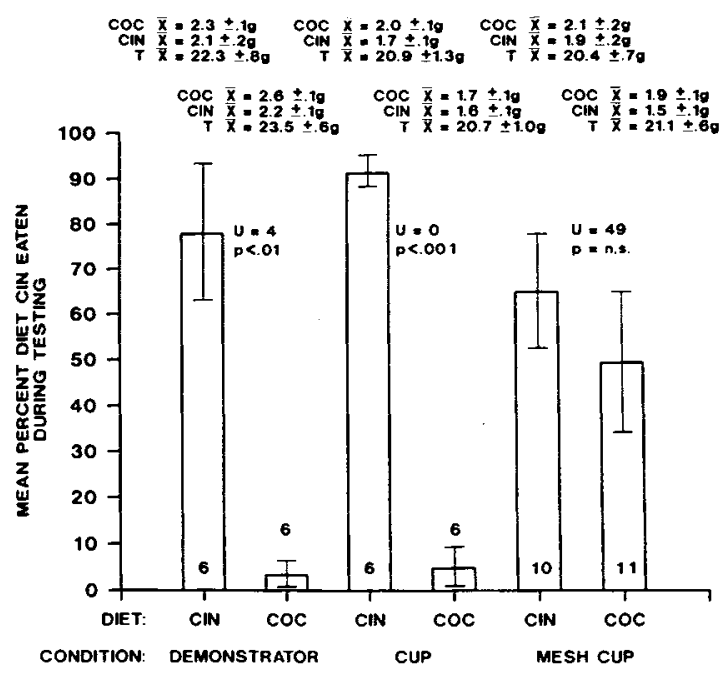

Figure 1. Mean amount of Diet CIN eaten by subjects, as a percentage of total amount consumed during testing (Step 7 of Procedure). Numerals at the bottom of the graph $=n$ /group. Means and $S E M s$ above histograms $=(1)$ the mean amounts \pm 1 SEM of Diet COC and Diet CIN eaten by subjects during Step 4, and (2) the mean total amounts (T) \pm 1 SEM eaten by subjects during Step 7 of Experiment 1. Flags on histograms $= \pm 1 S E M$. 
during Step 3 on their food choices during testing in Step 7.

The subjects that could smell a food but could not eat during Step 3 of the procedure did not exhibit a preference during testing for the diet placed in their cages during Step 3.

The results of Experiment 1 demonstrate that, using the present procedures, eating a small amount of a diet but not smelling a diet was as effective as was interacting with a demonstrator that has eaten a diet in enhancing subjects' later preferences for the diet to which they were exposed. In one sense, this finding is not surprising. It has been known for many years that exposure of a rat to a diet interferes with subsequent learning of an aversion to that diet (Kalat \& Rozin, 1973; Revusky \& Bedarf, 1967). However, considered in the context of previous analyses of social influences on diet selection by rats carried out in my laboratory, the results of the present experiment are unusual. The present results, unlike those of previous studies (Galef, 1986a, 1986b, 1987), are consistent with the hypothesis that social influences on diet choice might be the result of subjects' nibbling bits of food clinging to the fur or vibrissae of their respective demonstrators while interacting with them.

\section{EXPERIMENT 2}

Even if eating small amounts of food is sufficient to produce effects on food choices that are of similar magnitude to the effects that are produced by interaction with demonstrators, this does not mean that eating scraps of food from the coats of demonstrators is necessary to produce changes in subjects' diet preferences. In Experiment 2, I examined the effects of diets fed to demonstrators on the diet preferences of subjects when subjects and demonstrators interacted under conditions that prohibited the subjects from ingesting any food particles that may have clung to their demonstrators.

\section{Method}

Subjects. Seventy-eight 42-day-old female Long-Evans rats served as subjects in the present experiment. An additional 54 56day-old female rats that had served as subjects in other experiments served as demonstrators.

Apparatus. The apparatus used in Experiment 2 was that used in Experiment 1.

Procedure. The procedure of Experiment 2 was identical to that of Experiment 1, except during Step 3. In the present experiment, instead of allowing a subject and demonstrator to interact freely during Step 3 of the experiment, I anesthetized $(50-\mathrm{mg} / \mathrm{kg}$ Somnatol injected i.p.) each demonstrator after it had eaten either Diet CIN $(n=15)$ or Diet $\operatorname{COC}(n=15)$ for $1 \mathrm{~h}$, taped the demonstrator to a petri dish, and placed it on the far side of the screen partition from a subject, with the demonstrator's nose $2-3 \mathrm{~cm}$ from and facing the screen. Each demonstrator was placed so that the subject with which it interacted could not make physical contact with its demonstrator. The data from 1 subject was lost when it spilled excessive amounts of food during Step 7.

Each of 24 additional subjects interacted not with an anesthetized demonstrator fed Diet CIN or Diet COC, but with an anesthetized demonstrator that had had its face rolled in either Diet CIN $(n=12)$ or Diet COC $(n=12)$ before it was taped to a petri dish and placed on the far side of the screen partition from the subject to which it was then exposed. The data from 1 subject in this group was discarded when its demonstrator died following injection of anesthetic.

An additional 24 observers interacted during Step 3 with surrogate demonstrators that had been powdered with either Diet CIN or Diet COC. Surrogate demonstrators were constructed of rat-sized wads of cotton batting wrapped in seamless, tubular gauze (Size 12 Tubegauze, Scholl Canada Inc., Toronto, Ontario) stapled closed at one end. The closed end of a surrogate was rolled in either Diet CIN (12 surrogates) or Diet COC (12 surrogates) until it was liberally coated with diet, and each surrogate was then taped to a petri dish and presented to a subject in the same position that anesthetized subjects in other groups occupied relative to the subjects with which they interacted. Data from 1 subject that interacted with a surrogate was discarded when it failed to eat during Step 4 of the Procedure.

\section{Results and Discussion}

The main results of Experiment 2 are presented in Figure 2, which shows the mean amount of Diet CIN ingested, as a percentage of total amount eaten during testing (Step 7), by subjects exposed to anesthetized, fed demonstrators, to anesthetized, powdered demonstrators, or to powdered surrogates during Step 3 of the experiment.

As is evident from examination of Figure 2 and as statistical tests confirmed (Mann-Whitney $U$ tests; see Figure 2 for $U$ and $p$ values), the subjects that interacted at a distance with anesthetized demonstrators that had either eaten or been powdered with a diet exhibited a preference for the diets associated with their respective demonstrators. These subjects did not have to eat small samples of diet in order to develop a preference for the diet associated with a demonstrator.

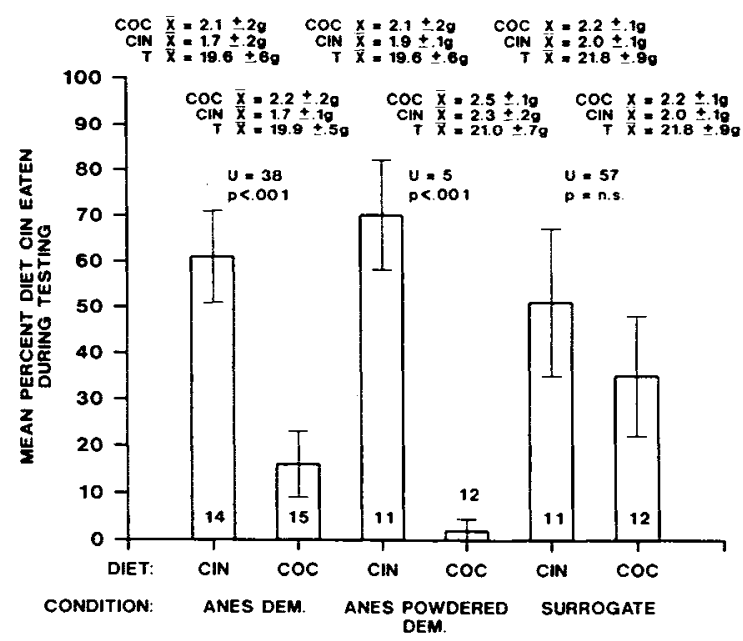

Figure 2. Mean amount of Diet CIN eaten by subjects, as a percentage of total amount consumed during testing (Step 7 of Procedure). Numerals at the bottom of the graph $=n$ /group. Means and $S E M s$ above histograms $=(1)$ the mean amounts \pm 1 SEM of Diet $C O C$ and Diet CIN eaten by subjects during Step 4 , and (2) the mean total amounts $(T) \pm 1 S E M$ eaten by subjects during Step 7 of Experiment 2. Flags on histograms $= \pm 1 S E M$. 
During testing, subjects that had interacted with surrogates did not exhibit a preference for the diet with which their respective surrogates had been powdered. Thus, in the present experimental situation, as in those described in Galef et al. (1985), Galef and Stein (1985), and Galef, Mason, Preti, and Bean (1988), as well as in Experiment 1 above, simply smelling a food was not effective in altering the diet preferences of subjects, whereas smelling the same food on a demonstrator rat was effective in altering subjects' diet preferences.

\section{GENERAL DISCUSSION}

In the course of their studies of social influences on diet choice in rats, Posadas-Andrews and Roper (1983) found that exposure of a rat to the smell of a food, like exposure of a rat to a conspecific that had eaten a food, increased preference for that food. Posadas-Andrews and Roper interpreted this result as indicating that the effect of interacting with a recently fed demonstrator rat on the later food preferences of observer rats was due to simple exposure of observers to diet-related odors carried on the fur or breath of demonstrators. Because exposure to the odor of a diet and exposure to a demonstrator that had eaten a diet produced the same effect on the diet preferences of observers, Posadas-Andrews and Roper concluded that the effect of interaction with a demonstrator could be explained entirely by the exposure of observers to diet odor carried on demonstrators. Posadas-Andrews and Roper undertook no further analyses of social effects on diet preference in rats.

The inference to be drawn from the results of the present experiments is that Posadas-Andrews and Roper's (1983) conclusion does not necessarily follow from their results. As was demonstrated in the present experiments, even if both exposure to a food and exposure to a demonstrator that has eaten a food cause similar changes in the food preferences of subjects, it cannot be inferred that demonstrator-induced changes in subjects' food preferences are the result of simple exposure to diets or to dietrelated cues carried by demonstrators.

Whether eating a food, smelling a food, or interacting with a demonstrator that has eaten a food will influence later food preferences seems to depend both on the parameters of exposure to diet-related cues and on the conditions of the test for the effects of exposure. If one wishes to demonstrate that either simple exposure to an odor or eating a food with a given odor alters later preference for foods having that odor, it is customary to use highly volatile odorants (peppermint extract, garlic extract, etc.) and to expose subjects to the relevant odor on numerous occasions before testing for alterations in preference (Capretta \& Rawls, 1974; Leon, Galef, \& Behse, 1977; Posadas-Andrews \& Roper, 1983).

Experimental procedures that minimize the effects of simple exposure to the smell of a food on later prefer- ence for that food (e.g., using a single, brief exposure to a weakly smelling odorant) permit the detection of changes in diet preference that result from processes other than simple exposure (Galef et al., 1985). Hence, under different conditions, one can demonstrate: (1) effects of demonstrators that have eaten a diet on subjects' later diet choices, when there are no similar effects resulting from subjects eating the diet (Galef, 1989; Galef et al., 1985), (2) effects of eating a diet on later diet choice when there are no effects of simply smelling the diet (Experiments 1 and 2 above), and (3) similar effects of smelling a diet and of interacting with a demonstrator that has eaten the diet (Posadas-Andrews \& Roper, 1983).

The observation that, under some conditions, either simply eating a diet or simply smelling a diet produces changes in diet preference similar to changes in diet preference produced by interacting with a demonstrator that has eaten a diet does not permit the inference that changes in diet preference induced by eating a diet, smelling a diet, and interacting with a demonstrator that has eaten a diet are all the result of simple exposure to the diet. As the outcomes of our studies of social influence on food preference make clear, eating a diet, smelling a diet, and interacting with a demonstrator that has eaten a diet can also have markedly different effects on later preference for that diet.

\section{REFERENCES}

Capretta, P. J., \& RAwls, L. H., III (1974). Establishment of flavor preference in rats: Importance of nursing and weaning experience. Journal of Comparative \& Physiological Psychology, 86, 670-673.

GALEF, B. G., JR. (1986a). Social identification of toxic diets by Norway rats (Rattus norvegicus). Journal of Comparative Psychology, 100, 331-334.

GALEF, B. G., JR. (1986b). Social interaction modifies learned aversions, sodium appetite, and both palatability and handling-time induced dietary preference in rats (Rattus norvegicus). Journal of Comparative Psychology, 100, 432-439.

GALEF, B. G., JR. (1987). Social influences on the identification of toxic foods by Norway rats. Animal Learning \& Behavior, 15, 327-332.

GALEF, B. G., JR. (1989). Enduring social enhancement of rats' preferences for the palatable and the piquant. Appetite, 13, 81-92.

GALEF, B. G., JR., \& KenNETT, D. J. (1987). Different mechanisms for social transmission of diet preference in rat pups of different ages. Developmental Psychobiology, 20, 209-215.

GAlef, B. G., JR., KennetT, D. J., \& STEIN, M. (1985). Demonstrator influence on observer diet preference: Effects of simple exposure and the presence of a demonstrator. Animal Learning \& Behavior, $13,25-30$.

Galef, B. G., JR., KennetT, D. J., \& Wigmore, S. W. (1984). Transfer of information concerning distant foods in rats: A robust phenomenon. Animal Learning \& Behavior, 12, 292-296.

Galef, B. G., JR., Mason, J. R., Preti, G., Bean, N. J. (1988). Carbon disulfide: A semiochemical mediating socially-induced diet choice in rats. Physiology \& Behavior, 42, 119-124.

Galef, B. G., JR., \& Stein, M. (1985). Demonstrator influence on observer diet preference: Analysis of critical social interactions and olfactory signals. Animal Learning \& Behavior, 13, 31-38.

GALEF, B. G., JR., \& WIGMORE, S. W. (1983). Transfer of information concerning distant food in rats: A laboratory investigation of the 'information centre' hypothesis. Animal Behaviour, 31, 748-758. 
HAlL, G. (1980). Exposure learning in animals. Psychological Bulletin, 88, 535-550.

HiLL, W. F. (1978). Effects of mere exposure on preferences in nonhuman mammals. Psychological Bulletin, 85, 1177-1198.

KAlat, J. W., \& Rozin, P. (1973). "Learned safety" as a mechanism in long-delay taste-aversion learning in the rat. Journal of Comparative \& Physiological Psychology, 83, 198-207.

Leon, M., GAlef, B. G., JR., Behse, J. H. (1977). Odor preexposure: Effects on ontogeny of phenomenal bonds and diet choice in rats. Physiology \& Behavior, 20, 135-140.
Posadas-Andrews, A., Roper, T. J. (1983). Social transmission of food preferences in adult rats. Animal Behaviour, 31, 265-276.

Revusky, S. H., \& BeDARF, E. W. (1967). Association of illness with prior ingestion of novel foods. Science, 155, 219-220.

(Manuscript received April 9, 1990; revision accepted for publication August 7, 1990.) 